\title{
Insight \\ Concomitant Patterns in Avian and Mammalian Body Length Changes in Denmark
}

\author{
$\underline{\text { Niels Martin Schmidt }}^{1}$ and $\underline{\text { Per Moestrup Jensen }}^{1}$
}

\begin{abstract}
We gathered length data on 61 Danish breeding birds from the past 200 years, and related the pattern of change to present body mass and other ecological parameters. Body mass was the only parameter significantly correlated with the rate of change, and the emerging pattern in the rate of change followed the island rule. That is, smaller species have become larger and vice versa, while the mediumsized species remain essentially unchanged. The suggested optimal body mass was around $85 \mathrm{~g}$. Though orders of magnitude lower, the pattern in avian body size change was similar to that of Danish mammals. Our analyses suggest that increasing habitat fragmentation leads to altered body size towards being mediumsized in Danish vertebrates. The changing landscape, thus, appears to be an important driver of body size changes in vertebrates.
\end{abstract}

Key Words: Body length; habitat fragmentation; island biogeography; island rule; Aves; reproductive output; migration; feeding category; competition; avoidance; tolerance.

\section{INTRODUCTION}

During the past two centuries, the landscape changes in Denmark have been substantial. For an area, which is considered representative for Denmark, Caspersen (2001) reported a decline from $46 \%$ to $3 \%$ in natural or semi-cultural habitats from 1815 to 1994 . From 1815 to 1880 , heath was reduced from $31 \%$ to $6 \%$, whereas arable land increased from $50 \%$ to $80 \%$. While the latter remained constant between $78-80 \%$ throughout the following century, the heath area steadily decreased. Riparian meadows maintained a $10 \%$ coverage from 1815 to 1880 but decreased to less than $1 \%$ in 1994. In contrast to this, the areas covered with forest increased from $5 \%$ in the nineteenth century to $12 \%$ and $19 \%$ in 1952 and 1994, respectively. Additionally, the borders between open land and areas such as forests became more well-defined and the intensification in management of both forests and agriculture has most likely led to an increased contrast between habitats (i.e., being either open and having bare soil part of the year or having dense permanent vegetation). It would be reasonable to expect that these changes have had a considerable impact on vertebrate communities. To define the change in structural properties of the Danish landscape for entire communities is, however, impossible due to the species-specific properties and habitat preferences.

Body size as a predictor of species sensitivity towards habitat fragmentation is ambiguous (Henle et al. 2004). In a recent paper (Schmidt and Jensen 2003), however, we reviewed recent changes in the body lengths of 25 Danish mammal species, and hypothesised that the observed pattern in body size change might be a consequence of the landscape changes in Denmark during the last 200 years. We found that on an ecological time-scale, Danish mammal species followed the island rule in response to these changes (i.e., smaller species getting bigger and larger getting smaller, while the medium-sized remain essentially unchanged) (van Valen 1973, Lomolino 1985). We did, however, also acknowledge that several other selective forces act on body size, too (Schmidt and Jensen 2003). To verify these initial observations we reviewed available records on the Danish breeding birds. 
Birds appeared to be suitable for this study because they also show indications of having an optimal body size. For example, the maximum densities are generally attained by medium-sized bird species (Brown 1995), and species richness also seems to peak in medium-sized bird groups (Brown et al. 1993). Also in a recent study, Clegg and Owens (2002) showed that on real islands changes in both avian body mass and bill length followed the island rule. Finally, Maurer (1998) reported the evolution of avian body size to be the result of non-random events, and possibly attracted towards the size that maximizes the reproductive output, as also suggested for mammals (Brown et al. 1993).

We expected Danish breeding birds to have experienced changes in their environment similar to those of the Danish mammals. A common pattern of body size change may imply a common causality. Hence, here we present data on avian body length changes in Denmark during the past 200 years, relate the pattern of change to body mass and compare the pattern of change to that of mammals.

\section{METHODS}

We extracted information on the body lengths of 61 bird species from nine scientific monographs covering almost 200 years (Fleischer 1796, Teilmann 1823, Walter 1828-1835, Paulsen 1842, Kjærbølling 1852, Hørring 1919, Heilmann and Manniche 1923, Salomonsen and Rudebeck 1964, Hvass 1978). All measurements were converted into metric units, and all data from species with nomenclature uncertainty were excluded. We used only data on Danish breeding species, and only unique data (i.e., data that were not repeated from earlier sources). In most cases, body length was given as an interval and we used the interval mean as the average body length. Separate measurements were not always available for both sexes. Sex dimorphism, however, is only pronounced in two of the 61 species (Goshawk and Sparrowhawk; Appendix 1), and body length therefore express the mean of the sexes.

As the sensitivity to habitat fragmentation may be related to the trophic position of a species (Henle et al. 2004), we assigned each species to one of three feeding categories (omnivore, herbivore/insectivore, carnivore). Moreover, birds staying in Denmark year-round may experience landscape changes differently than birds migrating out of Denmark for parts of the year. Hence, species were also categorized as either stationary or migratory, following Olsen (1992). Also, as observed for the Danish mammals (Schmidt and Jensen 2003), the reproductive output in birds may counteract the effects of habitat fragmentation, and the risk of extinction decreases with clutch size (Bennett and Owens 1997). Thus, we included reproductive output in our analyses. Present reproductive output was calculated as the mean number of eggs per clutch times the mean number of clutches per year. For all species, data on average present body mass, feeding category, and reproductive output were available at http://www.fugleinfo.dk.

The trend in body length change over time was calculated as in Schmidt and Jensen (2003). Hence, for each individual species, the annual rate of change equaled the slope of the linear regression on body length (percentage of present body length as in the 1978 data) as a function of time. We estimated the pattern of change using a general linear model with the annual rate of change as a response variable, and present body mass, trophic and migration categories, and present reproductive output as predictors. As a post hoc test we used Tukey's test for multiple comparisons.

Finally, we offer the present day species distribution of all Danish breeding birds (adapted from http://www.fugleinfo.dk) in relation to present body mass.

\section{RESULTS}

The body length measurements indicated body size changes in several of the 61 breeding bird species examined (Appendix 1). The temporal trend in body length size was significant in five species at the 0.10 level of significance, and in eight species at the 0.05 level of significance. On average, $6.2(\mathrm{SD}=0.98)$ length measurements were obtained for each of the 61 bird species (Appendix 1).

Present body mass was negatively correlated with the annual rate of change in avian body length (Fig. $1)$, and the linear regression line was statistically significant $\left(\mathrm{R}^{2}=0.10, \mathrm{~F}=6.65, \mathrm{P}=0.0125\right)$. Generally, small bird species have increased in size, whereas the larger species have decreased. Around the intermediary body mass of approximately $85 \mathrm{~g}$ $\left[\log _{10}(\right.$ body mass $\left.) \approx 1.92\right]$, only small changes in avian body length were found (Fig. 1). Excluding 
the two species with sex dimorphism (see above and Appendix 1), this did not affect the relationship markedly $\left(\mathrm{R}^{2}=0.0947, \mathrm{~F}=5.96, \mathrm{P}=0.0178\right)$ and only small changes in avian body length were found around a body mass of approximately $93 \mathrm{~g}$. Neither reproductive output, feeding nor migration had a significant impact on the annual rate of change $(\mathrm{P}$ $=0.548, \mathrm{P}=0.490$, and $\mathrm{P}=0.161$, respectively). Similarly, none of the interactions between the above predictors were significant $(\mathrm{P}>0.20)$.

The species distribution of the Danish breeding birds revealed a peak in species richness in species weighing between $11-100 \mathrm{~g}$ (Fig. 2).

\section{DISCUSSION AND SPECULATION}

The size changes in the 61 Danish bird species examined here display a pattern similar to that of the Danish mammals (Schmidt and Jensen 2003). Smaller species have generally become larger, whereas the larger species have become smaller. The medium-sized species have changed the least. Our analyses suggest that only limited change occur at an avian body mass of approximately $85 \mathrm{~g}$, which is comparable to the 'optimal' body mass suggested by Brown (1995), though somewhat larger. The optimal body size in birds was smaller than that of mammals (around $280 \mathrm{~g}$; Schmidt and Jensen 2003), as also suggested by Brown (1995). The largest deviations from expected pattern of body size change was found for the Black Grouse (Tetrao tetrix; Fig. 1), whose body size has been markedly reduced. The Black Grouse population has declined dramatically during the last 200 years (Olsen 1992), bringing the species to extinction in the 1990s. Hence, the large deviation from the expected body size changes may be seen as an indication of a species unable to adapt to its changing environment, and thus prone to extinction. Also, present day species richness was highest for medium-sized birds, a pattern also observed in other studies (e.g., Brown et al. 1993, Cardillo 2002). The peak number of species was found for birds weighing $11-100 \mathrm{~g}$ (Fig. 2) (i.e., the weight class including species with the suggested optimal body size). Unfortunately, we were unable to track possible changes in the species distribution of the bird assembly during the past 200 years.

Body mass was the only variable significantly associated with avian rate of change. In mammals, reproductive output seemed to work against the effect of habitat fragmentation (Schmidt and Jensen 2003). Also in birds, large reproductive output may counteract the effects of habitat fragmentation (Henle et al. 2004). And, as pointed out by Maurer (1998), reproductive output seems an important parameter in determining avian body size. However, amongst the Danish breeding birds, reproductive output seemed unimportant for the rate of body size change. Similarly, neither the trophic nor the migratory category affected the rate of change. This was unexpected as the effects of habitat fragmentation are likely to differ between feeding categories and between migrating and stationary birds.

Our analyses of vertebrate body size change in the past 200 years (Schmidt and Jensen 2003, this study) suggest that Danish birds and mammals do experience the increasing habitat fragmentation as island formation, leading to a pattern consistent with the island rule (van Valen 1973, Lomolino 1985). The avian rates of change, however, were orders of magnitude lower than those of mammals (Schmidt and Jensen 2003). For both vertebrate groups, however, the proportion of variance explained was rather low, indicating that along with the effects of habitat fragmentation several other factors play an important role in shaping vertebrate body size. For instance, a change in climate is likely to affect vertebrate body size. Since the end of the eighteenth century, the climate in Denmark has become generally milder. This, however, is not expected to affect the body size change in a manner similar to the observed pattern (i.e., towards an optimal body size unless it can work through the mechanisms driving the island rule). In Denmark, milder climate can also be seen as a relief from temporal disturbance (e.g., less severe winters and prolonged growing season). And certainly the distinction between temporal and spatial disturbance (i.e., island formation) may be crucial for the understanding of body size changes and its consequences. Morton (1990) found that in droughtaffected Australia, medium-sized mammals (i.e., those of the expected optimal size; Schmidt and Jensen 2003) were the species most prone to extinction, and suggested drought as the driving force in the observed extinctions. There the smaller mammals have increased fitness due to the ability to survive in very small patches, while larger mammals have increased fitness due to low cost of moving and locating new, suitable habitats (Morton 1990). The medium-sized mammals have intermediate life strategies and go extinct in the 
Fig. 1. Annual rate of change in body length (\% of present body length) in 61 Danish breeding birds, $1796-$ 1978 , versus present body mass. Also given is the regression line ( $\mathrm{Y}=0.000342-0.000178 \mathrm{X})$. The black dot indicates the rate of change for Black Grouse (Tetrao tetrix).

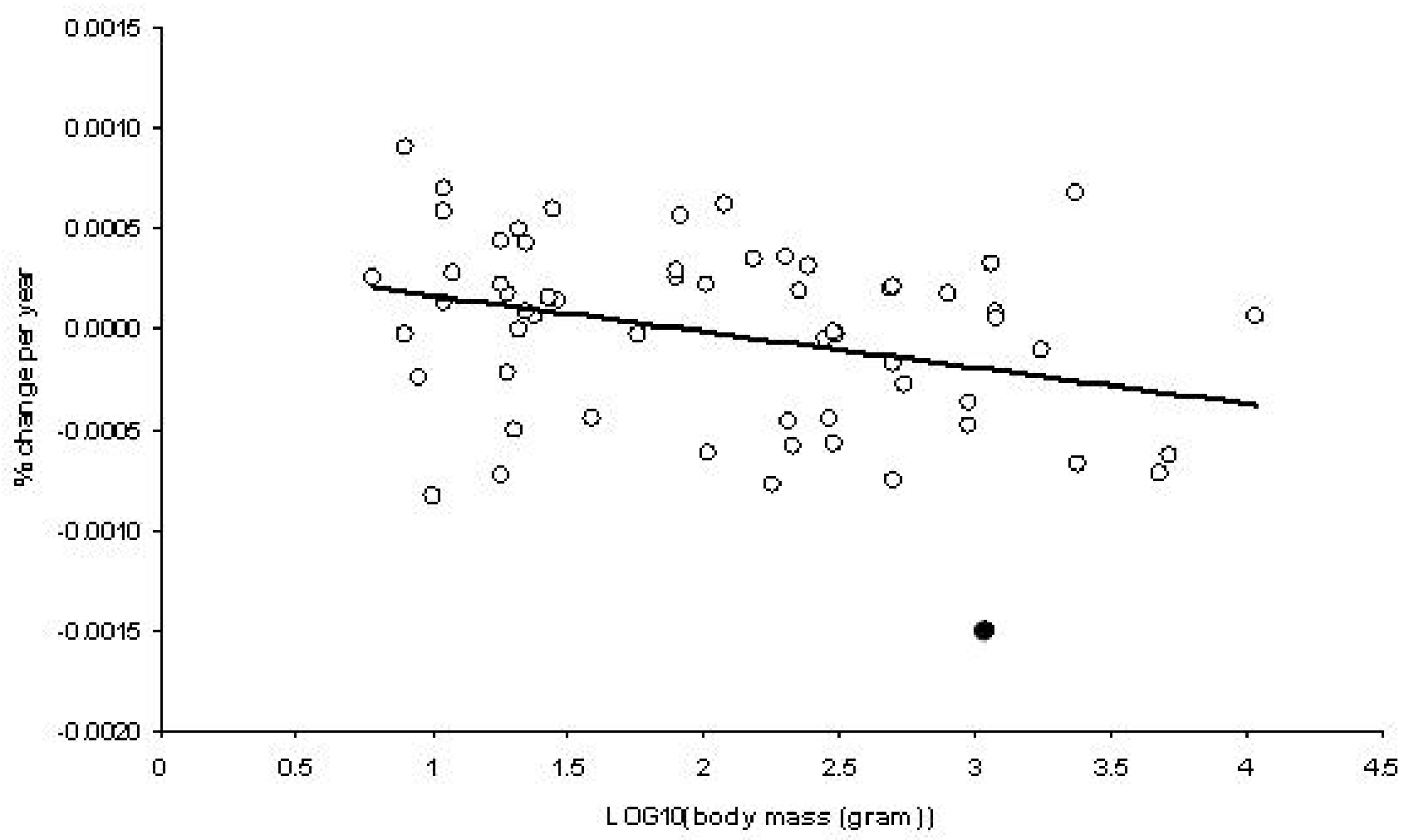

disturbed landscape. In other words, the larger mammals can be seen as being tolerant to the disturbances by moving between patches ("tolerants"), the smaller mammals as avoiding the disturbances by surviving within the patches ("avoiders"), while the medium-sized mammals are the competitors who depend on the availability of the resources ("competitors"). Therefore, a traditional dichotomy given by the well-known $r$ $\mathrm{K}$ strategy is inadequate, and a three-strategy categorization that parallels that proposed by Grime et al. (1988) seems more appropriate. Grime defined three extremes in the environmental settings (namely disturbed, stressed and benign) under which three specific life strategies [ruderal (i.e., avoiders), tolerant and competitive, respectively] would be favored. Later, Silverton et al. (1993) evaluated the demographic parameters growth, fecundity, and longevity as proxies for the life strategies, which is an acceptable simplification in plant communities. A similar classification framework was applied for animals by Winemiller and Rose (1992). Demographic parameters alone are not likely to provide sufficient information in animal communities due to the importance of behavioral traits in defining life strategies.

In Denmark, where island formation is permanent and temporal disturbance low due to the mild climate and possible increased eutrophication (European Environment Agency 1995), the body size changes towards being medium-sized probably 
Fig. 2. Present species distribution of 185 Danish breeding birds as a function of the log-transformed body mass. Data obtained from http://www.fugleinfo.dk.

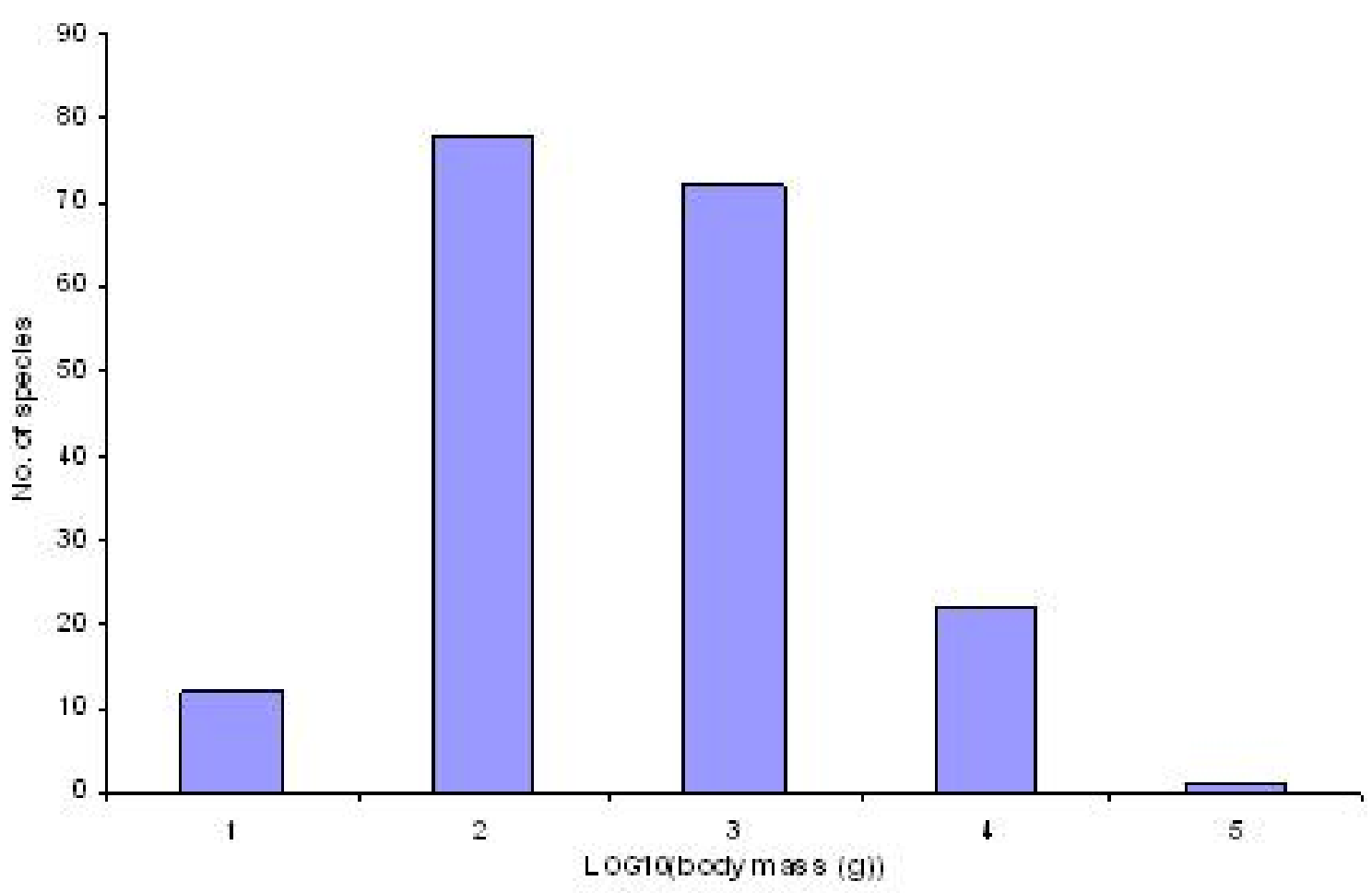

reflect competition for resources within habitat fragments rather than avoidance or tolerance for temporal disturbance as the favorable life strategy; whereas in Australia the competitors go extinct in the temporal varying islands.

To what extent the above considerations made for mammals apply to bird communities is unknown. Birds also perceive the landscape according to body mass (Hosteller and Holling 2000), but most landscape barriers become negligible by means of flying, and the costs associated with locating to new habitats are most likely insignificant for birds compared to mammals. Also, birds generally perceive their habitat three-dimensionally, while mammals generally perceive theirs in twodimension. Finally, compared to mammals, bird life strategy may be less coupled to body size.

In conclusion, there are evolutionary as well as ecological implications of the observed body size changes in the Danish vertebrate community. Further studies, especially in areas with a different history of landscape developments and climatic changes, are needed to fully evaluate these findings.

Responses to this article can be read online at:

http://www.ecologyandsociety.org/vollo/iss2/art5/responses/

\section{Acknowledgments:}

We thank P. Christiansen for assistance in providing the bird measurements, and K. M. Dromph for discussions and comments on the manuscript. The study was financially supported through the SNF program "Borders in the landscape" (J.no. 9500887). 


\section{LITERATURE CITED}

Bennett, P.M., and I.P.F. Owens. 1997. Variation in extinction risk among birds: chance or evolutionary preposition? Proceedings from the Royal Society of London. B. 264: 401-408.

Brown, J.H. 1995. Macroecology. The University of Chigaco Press, Chigaco, Illinois, USA.

Brown, J.H., P.A. Marquet, and M.L. Taper. 1993. Evolution of body size: consequences of an energetic definition of fitness. American Naturalist 142: 573-584.

Cardillo, M. 2002. Body size and latitudinal gradients in regional diversity of New World birds. Global Ecology and Biogeography 11: 59-65.

Caspersen, O. H. 2001. Landbrug og Landskab fra 1800 til 2000. In Hels T. Nielsson K., Frandsen J. N., Fritzbøger B., Olesen C. R., 2001. Granser $i$ Landskaber. Odense University Press, Denmark. (in Danish)

Clegg, S.M., and I.P.F. Owens. 2002. The island rule in birds: medium body size and its ecological explanation. Proceedings from the Royal Society of London, England. B. 269: 1359-1365.

European Environment Agency. 1995. Europe's Environment: The Dobris Assessment. In D. Stanners and P. Bourdeau, editors. Office for Official Publications of the European Communties, Luxembourg, Luxemburg.

Fleischer, E. 1796. Forsøg til en almindelig Naturhistorie. Vol. 8. Copenhagen, Denmark. (in Danish)

Grime, J.P., J.G. Hodgson, and R. Hunt. 1988. Comparative plant ecology: a functional approach to common British species. Oxford University Press, London, England.

Heilmann, G., and A.L.V. Manniche. 1928-1930. Danmarks Fugleliv. Vol. 1-3. Hage and Clausens Forlag, Copenhagen, Denmark. (in Danish)

Henle, K., K.F. Davis, M. Kleyer, C. Margules, and J. Settele. 2004. Predictors of species sensitivity to fragmentation. Biodiversity and Conservation 13: 207-251.
Hosteller, M., and C.S. Holling. 2000. Detecting the scales at which bords respond top structure in urban landscapes. Urban Ecosystems 4: 25-54.

Hvass, H. 1978. Danmarks Dyreverden. Rosenkilde and Bagger, Copenhagen, Denmark. (in Danish)

Hørring, R. 1919. Fugle. Vol. 1: Andefugle og hønsefugle. Danmarks Fauna, G.E.C Gads Forlag, Copenhagen, Denmark. (in Danish)

Kjærbølling, N. 1852. Danmarks Fugle. Copenhagen, Denmark. (in Danish)

Lomolino, M.V. 1985. Body sizes of mammals on islands: the island rule re-examined. American Naturalist 125: 310-316.

Maurer, B.A. 1998. The evolution of body size in birds: evidence for non-random diversification. Evolutionary Ecology 12: 925-934.

Morton, S.R. 1990. The impact of European settlement on the vertebrate animals af arid Australia: a conceptual model. Proceedings of the Ecological Society of Australia. 16: 114-121.

Olsen, K.M. 1992. Danmarks fugle - en oversigt. Dansk Ornitologisk Forening, Copenhagen, Denmark. (in Danish)

Paulsen, B.H.C.E. 1842. Veiledning til Kundskab om de i Danmark, Slesvig og Holsten forekommende fugle. En haandbog for Jægere, Jagtyndere og Landmænd. Copenhagen, Denmark. (in Danish)

Salomonsen, F., and G. Rudebeck. 1964. Danmarks Fugle. Vol. 1-2. Branner and Korch, Copenhagen, Denmark. (in Danish)

Schmidt, N.M., and P.M. Jensen. 2003. Changes in mammalian body length over 175 years adaptations to a fragmented landscape? Conservation Ecology 7: 6.

Silverton, J. W., M. Franco, I. Pisanty and A. Mendoza. 1993. Comparative plant demography relative importance of lifecycle components to the finite rate of increase in woody and herbacious perennials. Journal of Ecology 81: 465-476.

Teilmann, A.C. 1823. Fors $ø g$ til en Beskrivelse af 
Danmarks og Islands Fugle eller Haandbog i det Danske Veideværk. Ribe, Denmark. (in Danish).

van Valen, L.M. 1973. Pattern and the balance of nature. Evolutionary Theory 1: 31-49.

Walter, J.E.C. 1828-1835. Nordisk Ornithologie eller troværdige efter Naturen tegnede stukne og colorerede Afbildninger af Danske, Færøske, Grønlandske og Islandske fugle. Copenhagen, Denmark. (in Danish)

Winemiller, K.O., and K.A. Rose. 1992. Patterns of life-history diversification in North American fishes: implications for population regulation. Canadian Journal of Fisheries and Aquatic Sciences 49:2196-2218. 
Appendix 1. Length measurement data $(\mathrm{cm})$ and summary statistics from the analysis of avian body size changes during the past 200 years. Body mass is given in gram, while "Feed" and "Migrating" indicates feeding and migratory categories, respectively. Also given is the number of eggs per clutch and the average number of clutches per year. See text for further explanation.

Please click here to download file 'append1.xls'. 